\title{
Variations physiologiques des activités lipasiques et de la lipolyse spontanée dans les laits de vache, de chèvre et de femme : revue bibliographique
}

(suite)

par

Y. CHILLIARD*

\section{LIPASE ET LIPOLYSE SPONTANEE DANS LE LAIT DE CHEVRE}

Les travaux sur la lipolyse et les lipases du lait de chèvre sont beaucoup moins nombreux que ceux effectués sur vache. Les études les plus anciennes ont surtout porté sur la flaveur du lait de chèvre (test organoleptique) en particulier dans les pays scandinaves [revue 234].

En effet, alors que la lipolyse est surtout considérée comme un facteur négatif entraînant le rancissement du lait de vache, elle semble pouvoir contribuer au développement de la flaveur caractéristique des laits et fromages de chèvre du fait de la libération d'acides gras courts de 6 à 10 atomes de carbone. Une lipolyse trop poussée se traduira cependant par une détérioration du goût, comme chez la vache.

\section{A. Composants du système lipolytique}

10 Relation entre l'Activité lipasioue et la lipolyse sPontanéE

Des corrélations hautement significatives sont observées entre la lipolyse spontanée et l'activité LPL du lait de chèvre. Ainsi, ces deux paramètres présentent 45 à 65 p. 100 de variance commune dans les expériences rapportées dans le tableau 4.

* Laboratoire de la Production laitière, I.N.R.A.-C.R.Z.V. de Theix - 63110 Beaumont.

Première partie parue en janvier-février, p. 1-31. 


\section{$T A B L E A U 4$}

Corrélations entre la lipolyse spontanée et l'activité lipoprotéine-lipasique du lait de chèvre

Chèvres norvégiennes (BJORKE et CASTBERG, 1976) (1)
- Lait du matin
$r=0,68$
$(\mathrm{n}=83)$,
- Lait du soir
$\mathrm{r}=0,81$
$(\mathrm{n}=21)$.

Chèvres alpines françaises (Selselet-Attou, Chilliard, Bas et Morand-Fehr, 1980, non publié) (1)

- Lait du soir

$$
r=0,67 \quad(n=80) .
$$

(1) Huit chèvres dans chaque expérience, suivies au cours de la lactation. La lipolyse représente l'augmentation de la teneur en AGL du lait stocké pendant $24 \mathrm{~h}$ à $4^{\circ} \mathrm{C}$.

Cette différence d'avec le lait de vache reflète probablement des particularités du système lipolytique du lait de chèvre, dont nous essayerons de préciser ci-dessous quelques composants à partir des rares études effectuées à ce sujet.

\section{EtAT DES GLOBULES GRAS}

Les globules gras du lait de chèvre présentent des caractères spécifiques. Ils sont en particulier plus petits, en moyenne, que ceux de vache $[31,70,135]$. Toutefois, aucune étude n'a cherché à relier ces caractéristiques au développement de la lipolyse dans le lait de chèvre.

\section{$3^{\circ}$ LOCALISATION DE LA LIPASE DU LAIT}

La LPL du lait de chèvre est répartie pour environ 45 p. 100 dans la phase grasse $[32,224]$, contre seulement 5 à 30 p. 100 dans le lait de vache [40]. La distribution de la LPL du lait de chèvre dans la phase aqueuse est encore très mal connue. La proportion de LPL dans les micelles de caséines semble être beaucoup plus faible (8 p. 100) que chez la vache (77 p. 100) [224].

\section{$4^{\circ}$ ACTIVATEURS DE LA LIPASE ET/OU DE LA LIPOLYSE}

Comme dans le lait de vache (fig. 3), la lipolyse du lait de chèvre est fortement stimulée par un apport de sérum sanguin in vitro. La stimulation maximale est atteinte pour une addition d'environ 10 p. 100 de sérum sanguin, avec un $\mathrm{Km}$ apparent d'environ 3 p. 100 de sérum [224].

Des mélanges de laits présentant une forte lipolyse (laits susceptibles thermisés, LST) avec des laits « normaux » frais (LNF) n'ont toutefois pas permis de mettre en évidence la présence dans les LS d'activateurs éventuels de la lipolyse des LN (fig. 11). L'intervention 


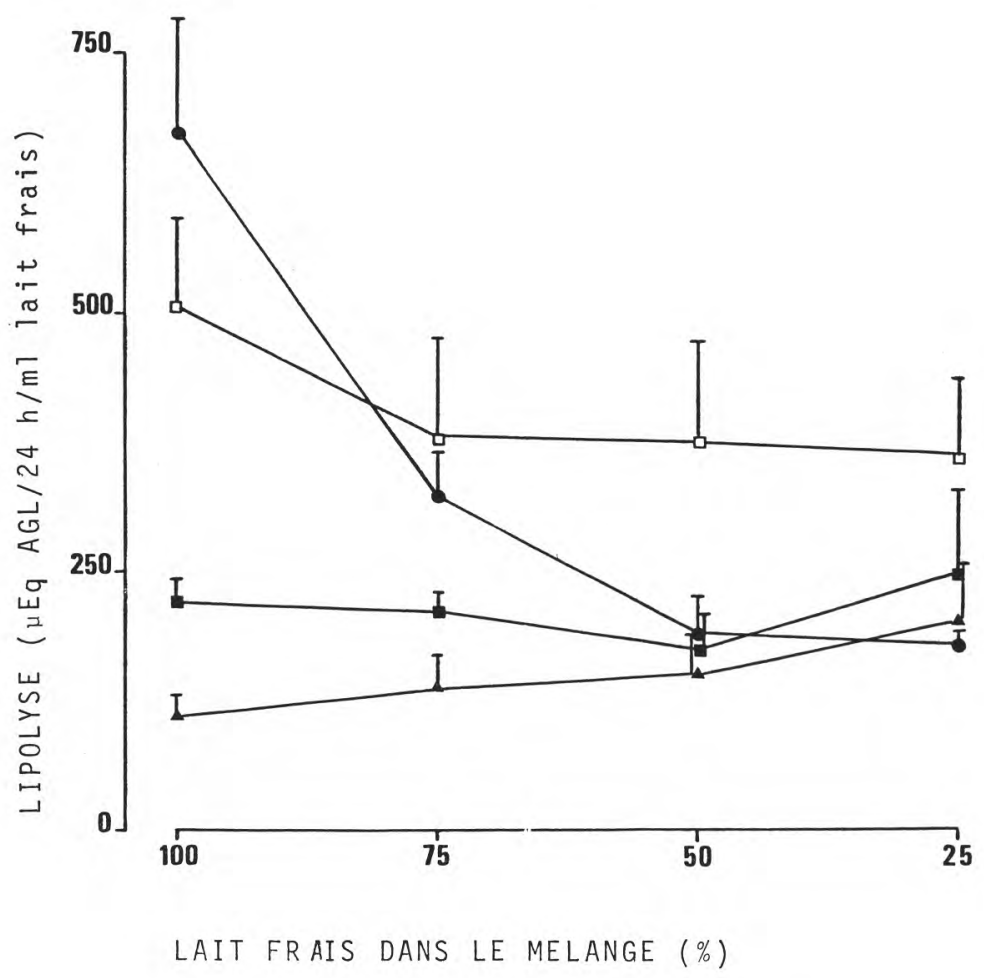

fig. 11

Lipolyse dans des mélanges de laits de chèvre

(Selselet-Attou, Chilliard, Bas et Morand-Fehr, 1980 [224], non publié).

- $=\mathrm{LSF}+$ LNT $(\mathrm{n}=7)$.

a $=$ LNF + LNT $(n=5)$.

$\Delta=\mathrm{LNF}+\mathrm{LST}(\mathrm{n}=6)$.

ㅁ $=\mathrm{LF}+$ sérum de Jenness $(\mathrm{n}=6)=$ témoin.

LS = laits présentant une lipolyse spontanée comprise entre 0,45 et $1,2 \mathrm{mEq} \mathrm{AGL} / 24 \mathrm{~h} / 1$.

$\mathrm{LN}=$ laits présentant une lipolyse spontanée comprise entre 0,1 et $0,3 \mathrm{mEq} \mathrm{AGL} / 24 \mathrm{~h} / \mathrm{l}$.

$\mathrm{F}=$ frais.

$\mathrm{T}=$ thermisés $30 \mathrm{~min}$. à $60^{\circ} \mathrm{C}$, de façon à détruire l'activité lipasique. La moyenne et l'erreur-type sont représentées.

d'activateurs d'origine sanguine dans le lait « in vivo » reste donc à démontrer.

Par ailleurs, la lipolyse spontanée du lait de chèvre n'est pas augmentée par addition d'héparine, quelles que soient les doses employées, les animaux ou les stades de lactation étudiés [224]. Des 
études supplémentaires sont nécessaires pour essayer de relier cette différence avec le lait de vache à la distribution de la LPL dans le lait de chèvre, en particulier à sa moindre liaison avec les micelles de caséine.

\section{$5^{\circ}$ INHIBITEURS DE LA LIPASE ET/OU DE LA LIPOLYSE}

Des mélanges de laits normaux thermisés avec des laits susceptibles frais suggèrent que certains LN puissent contenir un (des) inhibiteur(s) thermostable(s) de la lipolyse (fig. 11), comme dans le cas du lait de vache. Ces inhibiteurs semblent être situés dans la phase aqueuse du lait, en particulier dans le lactosérum, les protéosespeptones et, dans une moindre mesure, dans les caséines [224]. Ceci pose, là aussi, le problème de la non-spécificité éventuelle de ce type d'inhibition (cf. § III A.5.b).

La présence d'inhibiteurs de la lipolyse dans le lait pourrait par ailleurs être un phénomène assez répandu. Wallinder et al. [255.] ont par exemple observé que le lait écrémé de cobaye a une action inhibitrice sur la LPL.

\section{$6^{\circ}$ Activité LIPOGÉNIQUE DU LAIT}

Le lait de chèvre fraîchement sécrété est particulièrement riche en fragments cytoplasmiques [263, 262] qui présentent une activité métabolique importante, en particulier une forte activité de synthèse des glycérides $[171,54,55,252,163]$. Une telle activité lipogénique pourrait expliquer certaines diminutions de teneurs en AGL du lait de chèvre après la traite (Mahieu, communication personnelle), comme dans le cas du lait de vache. Ce résultat n'a toutefois pas été confirmé par les études de Selselet-Attou et al. [224].

\section{B. Variations physiologiques de l'activité lipasique et de la lipolyse spontanée dans le lait de chèvre.}

$1^{\circ}$ VARIATIONS INDIVIDUElles ET A COURT TERME

De grandes variations sont observées d'un animal à l'autre et d'un jour à l'autre, comme chez la vache. Toutefois, l'activité LPL [48, 49] et la lipolyse spontanée [224] semblent assez reproductibles d'une lactation à l'autre chez un même animal.

Un effet race (1), et un effet génétique intra-race semblent exister (tab. 5). Bjorke et Castberg [32] ont notamment montré une liaison

(1) Nous avions précédemment [48] fait l'hypothèse que la différence entre les activités LPL des chèvres norvégiennes et alpines puisse provenir d'un effet des sérums sanguins utilisés pour le dosage. En fait, le sérum humain utilisé pour activer le substrat ne permet qu'un accroissement de 3 à 15 p. 100 de l'activité LPL mesurée avec du sérum caprin (CHILLIARD, non publié). En outre, les différences dans les niveaux de lipolyse mesurés parallèlement permettent de penser qu'il s'agit effectivement d'un effet race et non d'un artéfact méthodologique. 


\section{TABLEAU 5}

Influence des facteurs génétiques sur la lipolyse du lait de chèvre

\begin{tabular}{|c|c|c|c|}
\hline & $\begin{array}{c}\text { Flaveur } \\
\text { (note de } \\
\text { dégustation) }\end{array}$ & $\begin{array}{c}\text { Lipolyse } \\
\text { spontanée } \\
\text { (mEq } \\
\text { AGL/1/24 h } \\
\text { ou } 36 \mathrm{~h})\end{array}$ & $\begin{array}{c}\text { Activité } \\
\text { LPL } \\
(\mu \mathrm{Eq} \\
\mathrm{AGL} / \mathrm{h} / \mathrm{ml})\end{array}$ \\
\hline \multirow{2}{*}{$\begin{array}{l}\text { Chèvres norvégiennes } \\
\text { Tout venant }\end{array}$} & & & \\
\hline & $1,6(1)$ & $\begin{array}{r}4,6(1) \\
(0 \text { à } 4,5)(2)\end{array}$ & $\begin{array}{l}70(2) \\
(0 \text { à 150) }\end{array}$ \\
\hline Lignée sélectionnée pour la flaveur & $2,5(3)$ & $5,6(3)$ & élevée (4) \\
\hline Lignée sélectionnée contre la flaveur & $2,1(3)$ & $2,7(3)$ & faible (4) \\
\hline Chèvres Saanen & $1,1(1)$ & $1,1(1)$ & - \\
\hline Chèvres Alpines & - & $\begin{array}{c}0,5(5) \\
(0 \text { à } 3,0)(5,6)\end{array}$ & $\begin{array}{l}35(5,6) \\
(0 \text { à } 80)\end{array}$ \\
\hline Vaches & $1,0(1)$ & $\begin{array}{r}0,7(1) \\
0,5 \text { à } 8,0(7)\end{array}$ & 0 à $400(8)$ \\
\hline \multicolumn{4}{|l|}{ (1) SKJEVDAL, 1979.} \\
\hline \multicolumn{4}{|l|}{ (2) BJORKE et CASTBERg, 1976.} \\
\hline \multicolumn{4}{|l|}{ (3) BAKKE et al.,1977. } \\
\hline \multicolumn{4}{|c|}{ (4) BJORKE, 1974 (cité par BAKKE et al., 1977). } \\
\hline \multicolumn{4}{|c|}{ (5) Selselet-Attou, Chilliard, Bas et Morand-Fehr, 1980, non publié. } \\
\hline \multicolumn{4}{|c|}{ (6) Chilliard et Morand-FeHr, $1978 \mathrm{a}$, et non publié. } \\
\hline \multicolumn{4}{|c|}{ (7) Voir les références citées dans le paragraphe III. } \\
\hline \multicolumn{4}{|c|}{$\begin{array}{l}\text { (8) KORN, 1962 ; ASKEW et al., } 1970 \text {; EGELRUd et OLIVECRONA, } 1972 \text {; HoYNes et } \\
\text { DOWNEY, 1973 ; RAO et al., } 1973 \text {; CASTBERG et SolBERG, 1974 ; CASTBERG et al., } \\
1975 \text {; SALIH et ANDERSON, } 1979 \text { a, b ; CHILLIARD, 1981, non publié. } \\
\text { Il est possible que la variabilité des activités LPL observées par les différents } \\
\text { auteurs soit due en partie à des problèmes méthodologiques. }\end{array}$} \\
\hline
\end{tabular}

inter-chèvre entre l'activité LPL, la lipolyse spontanée, la flaveur du lait et la teneur en acides gras courts des AGL du lait. L'ensemble de ces données confirme que la lipolyse spontanée et l'activité LPL jouent un rôle important dans le développement du goût du lait de chèvre conservé à $4^{\circ} \mathrm{C}$. En outre, les chèvres sélectionnées pour la flaveur du lait présentent des laits riches en acide palmitique, en AGL et en LPL $[19,238]$.

La lipolyse (comme chez la vache) et l'activité LPL sont plus élevées dans le lait du soir que du matin [32]. Bjorke et Castberg [32] 
n'observent pas de variations de l'activité LPL au cours de la traite. La même constatation a été faite par Chilliard et Fehr [47] en comparant les 250 premiers et derniers millilitres récoltés à la traite, mais ces auteurs ont observé une différence significative en comparant des fractions de $100 \mathrm{ml}$ (tab. 6). Cette différence avec le lait de vache (cf. § III B.1.) pourrait être liée à la présence de LPL dans la phase grasse du lait de chèvre, puisque le taux butyreux du lait augmente au cours de la traite [158].

\section{TABLEAU 6}

Evolution de l'activité lipoprotéine-lipasique du lait de chèvre au cours de la traite

(Chilliard et MORAND-FeHr, 1978 a)

\begin{tabular}{|c|c|c|}
\hline \multicolumn{2}{|c|}{ Activité LPL en début de traite $(\mu \mathrm{Eq} \mathrm{AG} / \mathrm{h} / \mathrm{ml})$} & $13,3 \pm 8,9^{*}$ \\
\hline \multicolumn{2}{|c|}{ Activité LPL en fin de traite } & $18,2 \pm 10,9$ \\
\hline Effet & $\begin{array}{l}\text { Seuil de } \\
\text { signification }\end{array}$ & $\begin{array}{l}\text { Part de dispersion des } \\
\text { résultats expliquée (p.100) } \\
\text { (degrés de liberté) }\end{array}$ \\
\hline — stade de traite & $\mathrm{P}<0,001$ & $7,1(1)$ \\
\hline - chèvre (individuel) & $\mathrm{P}<0,001$ & $88,9(4)$ \\
\hline - doubles d'incubation & $P>0,25$ & $0,1(1)$ \\
\hline - résiduel & & $3,9(13)$ \\
\hline
\end{tabular}

* Moyenne \pm écart-type.

Environ $100 \mathrm{ml}$ de lait sont prélevés manuellement au début et à la fin de la traite, chez cinq chèvres.

\section{VARIATIONS AU COURS DE LA LACTATION}

Le colostrum de chèvre présente une faible activité lipolytique ayant les caractéristiques de la LPL [46, 47] (fig. 12).

Cette activité LPL est faible pendant les premières semaines puis augmente de façon variable au cours de la lactation, pour chuter rapidement après la $30^{\mathrm{e}}$ semaine de lactation (fig. 12).

La lipolyse spontanée évolue d'une façon semblable (fig. 13), ce qui explique en partie les corrélations positives observées avec la LPL, mais cette évolution est moins brutale en début et en fin de 


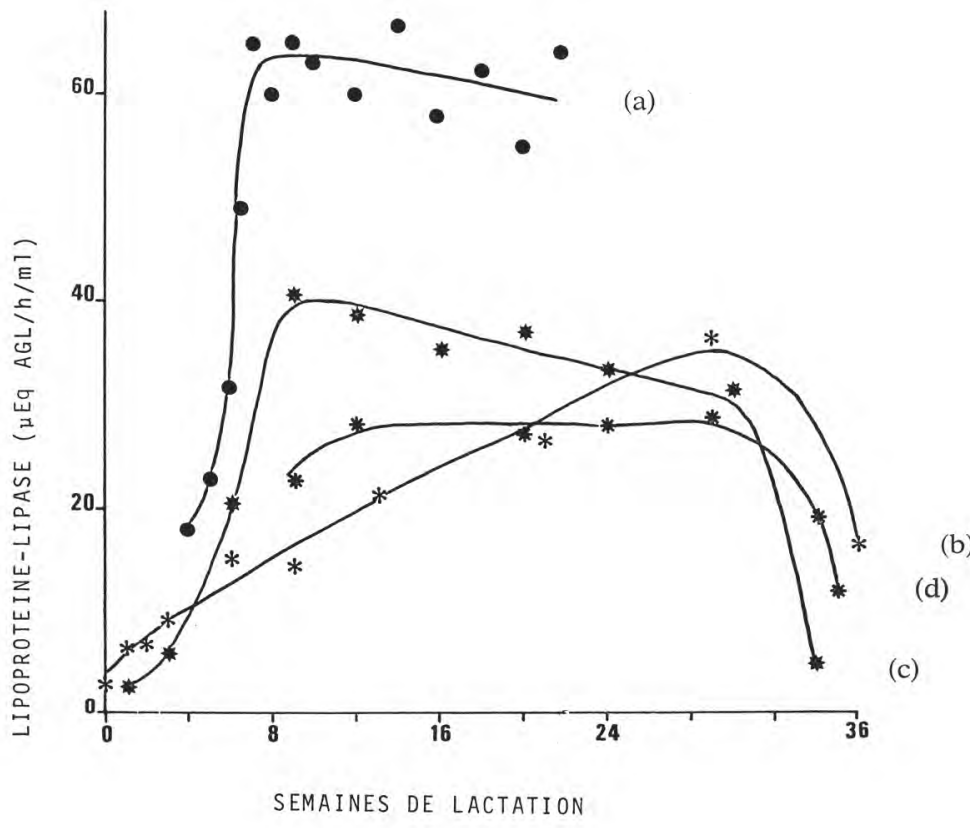

fig. 12

Evolution de l'activité lipoprotéine-lipasique (LPL) du lait de chèvre au cours de la lactation

(a) 8 chèvres norvégiennes (BJORKE et CASTBERg, 1976 [32] et communication personnelle).

(b) 128 échantillons provenant de 19 chèvres alpines $\left(\begin{array}{lll}5 & \text { à } & 17\end{array}\right.$ animaux par point) (CHILLIARD et MORAND-FEHR 1976 b [47], 1978 a [48] et non publié ; CHILliaRd et al., 1979 [53]).

(c) 8 chèvres alpines (Chilliard et Selselet-Attou, 1980, non publié).

(d) 24 chèvres alpines (Selselet-Attou, Chilliard, Bas et MorandFEHR, 1981, non publié).

lactation. Ce résultat est à rapprocher des observations rapportées par Skjevdal [234] selon lesquelles la flaveur du lait de chèvre est minimale en début et en fin de lactation.

La lipolyse stimulée par le sérum sanguin, in vitro, est très liée à l'activité LPL des laits des différentes chèvres aux différents stades de lactation (fig. $13 ; \mathrm{r}=0,91, \mathrm{n}=40$ ). Ceci confirme l'hypothèse selon laquelle l'effet du sérum sanguin se produit par l'intermédiaire de la LPL présente dans le lait et de son interaction avec la matière grasse. Il apparaît en outre que l'action de la LPL n'est pas optimale dans le lait normal, malgré les corrélations significa- 


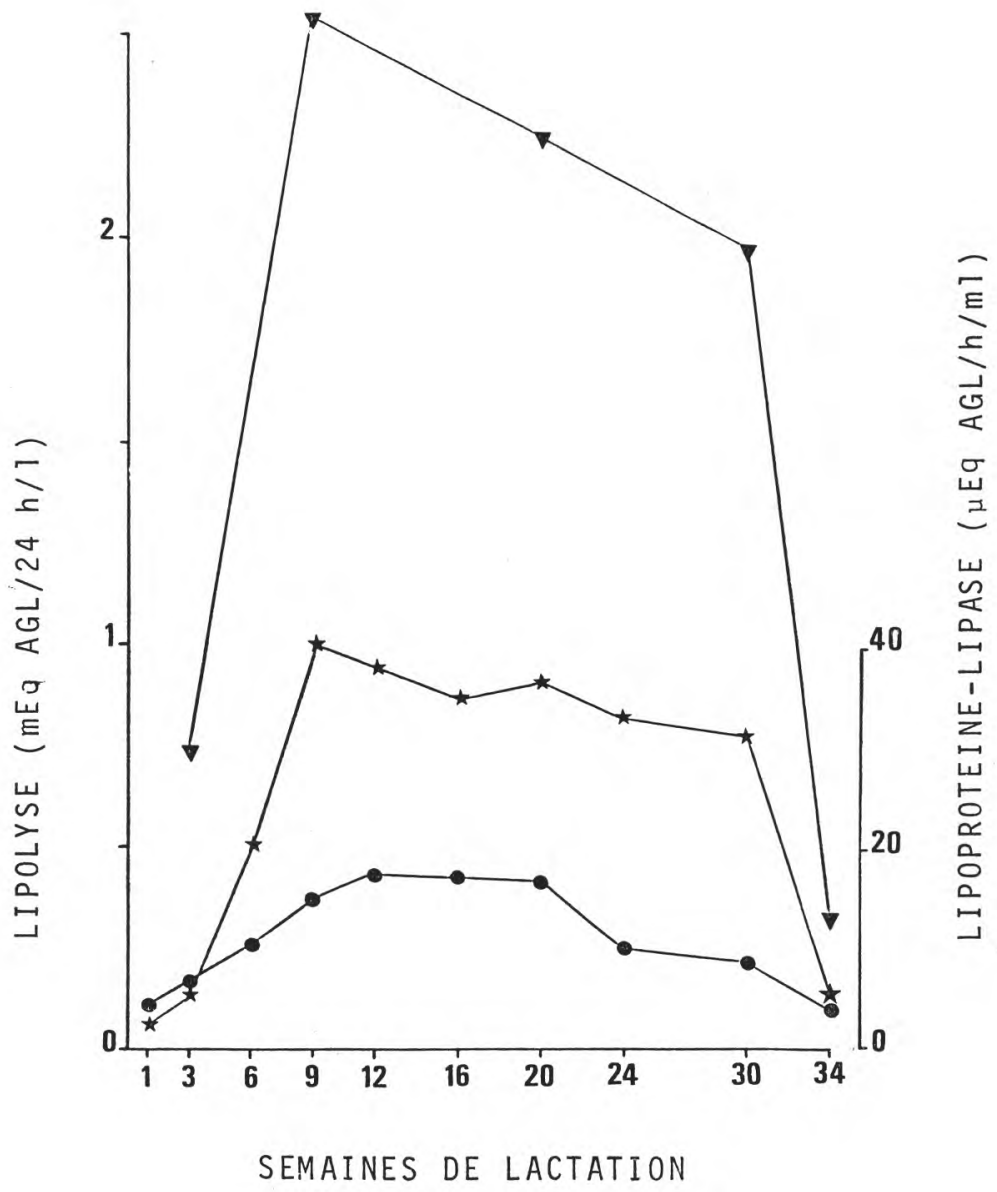

fig. 13

Evolution au cours de la lactation de la lipolyse spontanée (•) de la lipolyse activée par le sérum sanguin (10 p.100) ( $\mathbf{\nabla})$ et de l'activité LPL ( $\left.{ }^{\star}\right)$ du lait de 8 chèvres.

(Selselet-Attou, Chilliard, Bas et Morand-Fehr, 1980 [224], non publié).

tives avec la lipolyse spontanée chez la chèvre. Il faut remarquer à ce propos que la stimulation relative de la lipolyse spontanée par le sérum sanguin est d'autant plus élevée que celle-ci est faible (fig. 14) suggérant que les laits présentant de faibles lipolyses spontanées sont pauvres en cofacteurs de la LPL. Toutefois, cette relation n'est pas observée avec les laits de début et de fin de lactation ayant une faible activité LPL (fig. 14), probablement parce que dans ce cas c'est 


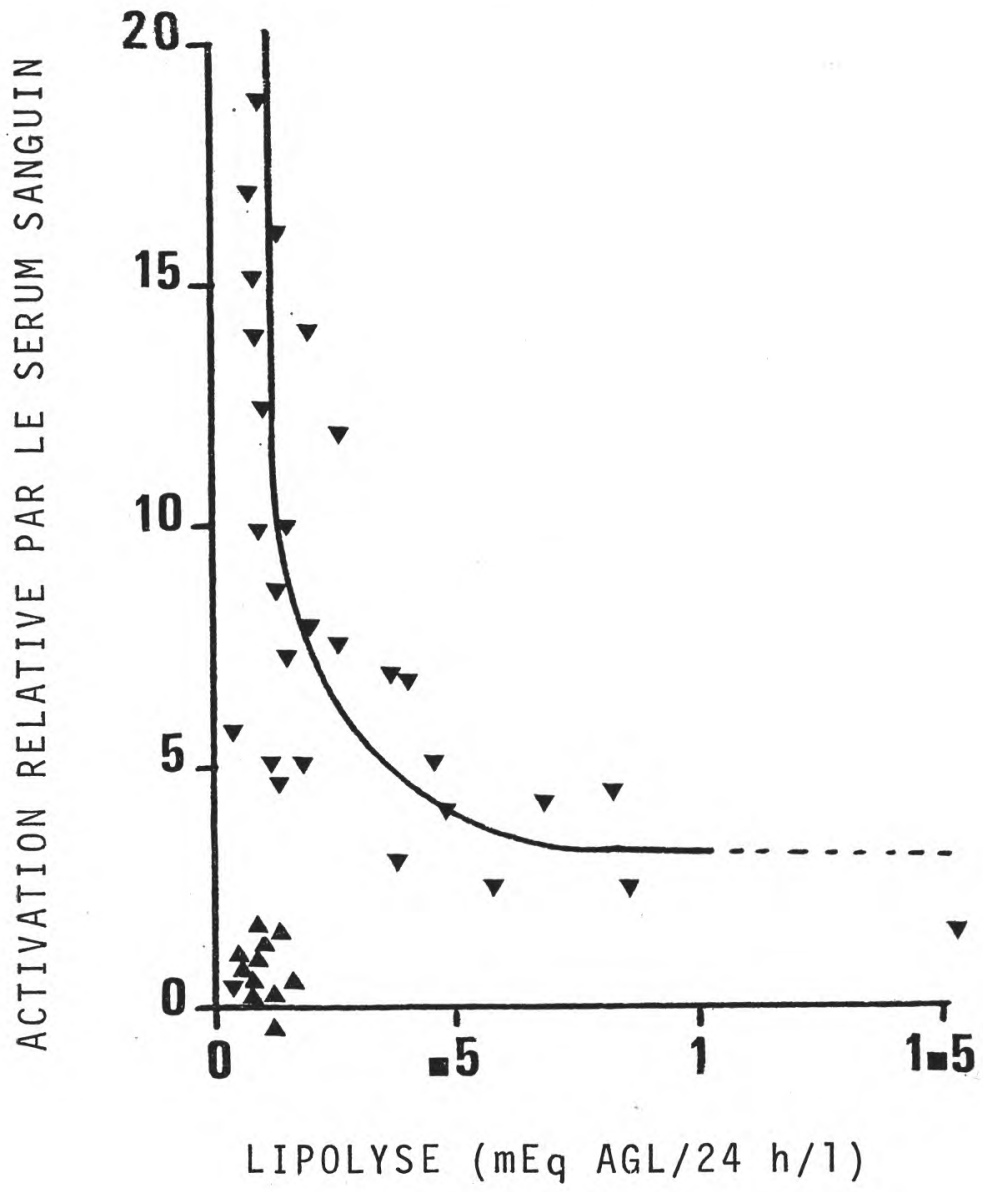

fig. 14

Relation entre la lipolyse spontanée du lait et son activation par le sérum sanguin chez la chèvre

(Selselet-Attou, Chilliard, Bas et Morand-Fehr, 1980 [224], non publié). Laits de 8 chèvres en $3^{\mathrm{e}}, 9^{\mathrm{e}}, 20^{\mathrm{c}}, 30^{\circ}$ et $34^{\mathrm{e}}$ semaine de lactation $(\boldsymbol{\nabla}, \mathbf{\Delta})$. Activation $=$ (lipolyse avec sérum - lipolyse spontanée)/lipolyse spontanée.

\ Lait de $3^{\mathrm{e}}$ ou de $34^{\mathrm{e}}$ semaine de lactation, ayant une activité $\mathrm{LPL}<4, \mu \mathrm{Eq}$ AGL $/ \mathrm{h} / \mathrm{ml}$.

la quantité de LPL présente dans le lait qui est le facteur limitant de la lipolyse, et non la présence de cofacteurs.

L'activité LPL semble être plus faible dans le lait de chèvres non gravides induites en lactation par un traitement hormonal que 


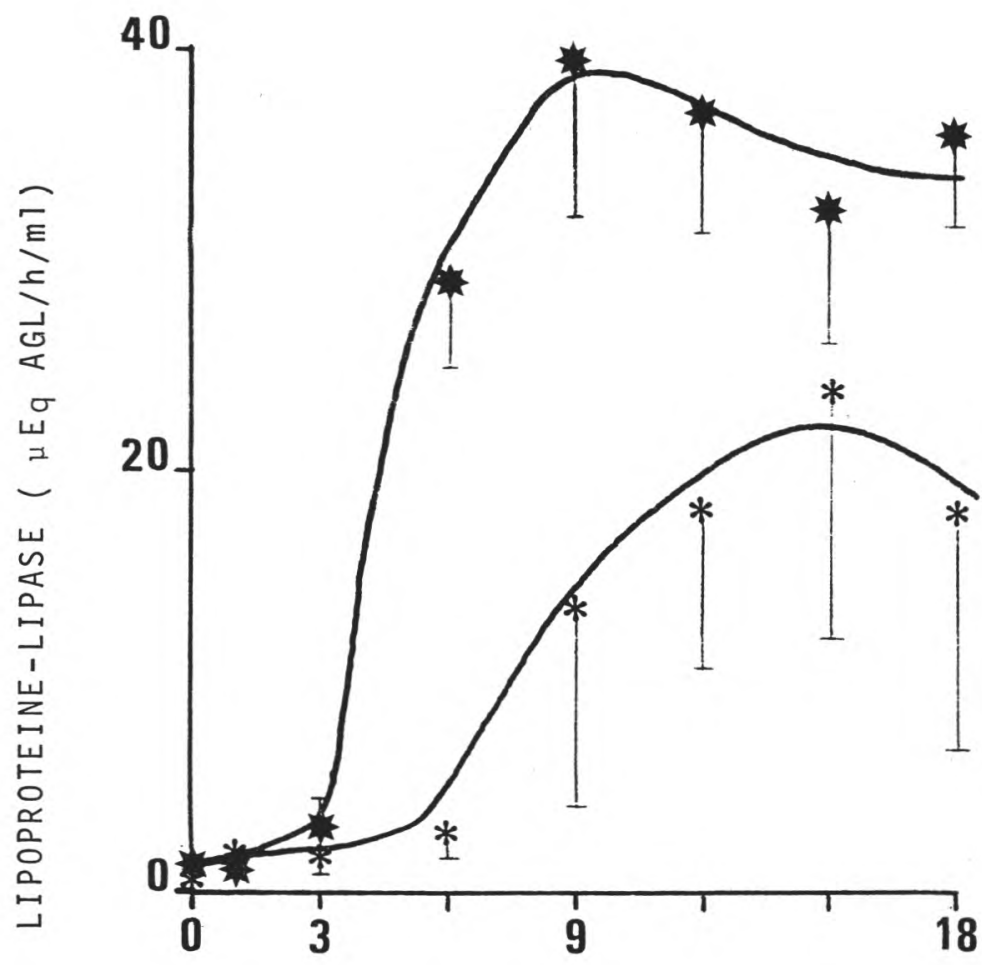

\section{SEMAINES DE LACTATION}

fig. 15

Influence de l'induction hormonale de lactation sur l'activité LPL du lait de chèvre

(Chilliard, Delouis, Smith, Sauvant et Morand-Fehr, 1980, non publié).

$\star 4$ chèvres après mise-bas.

* 4 chèvres non gravides ayant reçu des injections d'œstradiol et de progestérone (J-21 à J-15) et d'hydrocortisone (J-4 à J-1).

La moyenne et l'erreur-type sont représentées.

dans le lait de chèvres produisant du lait après avoir été gravides (fig. 15). Cette différence pourrait être reliée à l'état physiologique des animaux, mais aussi à la plus forte activité LPL du tissu adipeux des chèvres normales en pleine lactation (Chilliard, Delouis et al., 1980, non publié) (voir ci-dessous).

Par ailleurs, les variations observées au cours de la lactation expliquent en partie les corrélations négatives observées entre le 

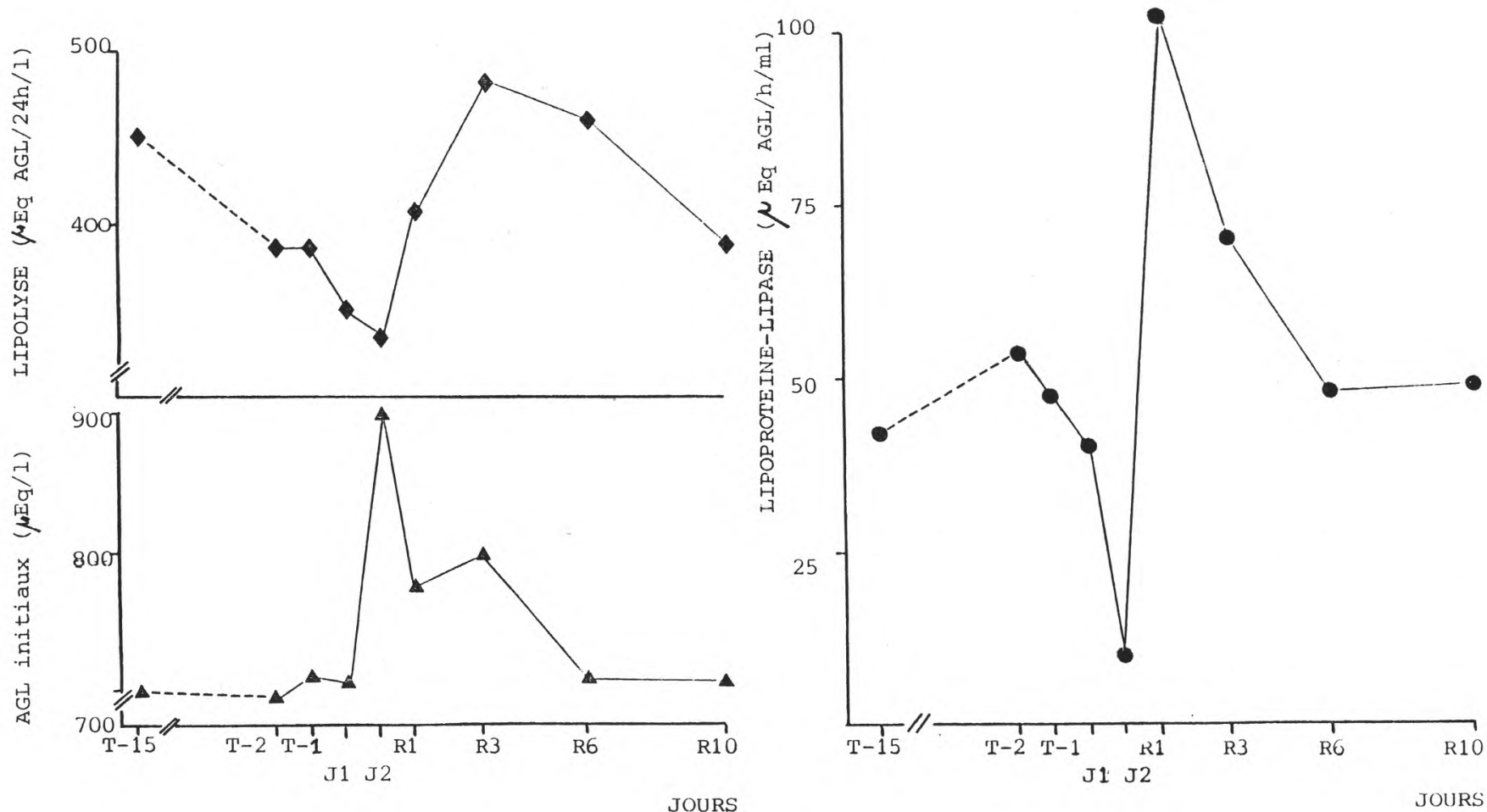

fig. 16

Influence du jeûne et de la réalimentation sur la teneur du lait frais en acides gras libres, la lipolyse post-traite et l'activité lipoprotéine-lipasique du lait de chèvre (SELSELET-ATtou, Chilliard, Bas et MoRAnD-FeHR, 1981, non publié)

$\mathrm{T}=$ Témoin

$\mathrm{J}=$ Jeûne

$\mathrm{R}=$ Réalimentation. Résultats obtenus sur 3 chèvres.

L'activité LPL du tissu adipeux diminue au cours du jeûne et augmente au cours de la réalimentation (CHILliaRD et al., 1979 [53] et non publié). 
taux butyreux d'une part et la flaveur du lait [234] et l'activité LPL [48] d'autre part.

\section{3o InFLUENCE DE L'ALIMENTATION}

L'influence des facteurs alimentaires sur la lipolyse du lait de chèvre est encore très mal connue. Les données relatives à la flaveur du lait dans les conditions norvégiennes ont été rassemblées par Skjevdal [234] et il apparaît notamment que celle-ci augmente lorsque les animaux ingèrent un supplément d'aliment concentré ou, plus généralement, d'énergie.

L'activité LPL du lait chute brutalement lorsque les chèvres sont mises à jeun pendant $48 \mathrm{~h}$ de façon à reproduire le cas d'une sousalimentation en pleine lactation [47, 48, 49] (fig. 16). Pendant le jeûne, les AGL initiaux du lait augmentent, alors que la lipolyse posttraite diminue légèrement (fig. 16), si bien que les AGL totaux du lait après $24 \mathrm{~h}$ de stockage augmentent peu (+ 15 p. 100 environ).

Au cours de la réalimentation, l'activité LPL présente un rebond très marqué $(24 \mathrm{~h}$ ) puis se stabilise au niveau témoin, les AGL initiaux reviennent au niveau témoin et la lipolyse post-traite augmente légèrement pendant $3 \mathrm{j}$ environ avant de se normaliser (fig. 16).

Il semble donc qu'au cours du jeûne la mamelle sécrète moins de LPL. Par ailleurs, elle produit plus d'AGL (prélèvement accru d'acides gras non estérifiés sanguins en raison de la lipomobilisation, accompagné d'une saturation de la capacité de la mamelle à estérifier ces acides gras ?). L'influence du jeûne et de la réalimentation sur la lipolyse post-traite est peu marquée et n'est pas entièrement expliquée par l'évolution de l'activité LPL.

La distribution de lipides insaturés protégés tend à diminuer la lipolyse spontanée et l'activité LPL du lait de chèvre en début de lactation (fig. 17). Skjeval [234] a par ailleurs rapporté que la flaveur du lait de chèvre est corrélée négativement avec sa teneur en acides gras polyinsaturés. Comme chez la vache, ces observations pourraient être liées à une diminution de la teneur des matières grasses du lait en acide palmitique [176]. Toutefois, la chèvre en fin de lactation ne semble pas répondre comme la vache à un apport d'acide palmitique dans le régime et présente alors une lipolyse plus faible (Astrup, 1979, communication personnelle).

4. Relations entre les activités LPL du lait, DE la MAMElle ET DU TISSU ADIPEUX

Les mécanismes de la sécrétion de la LPL du lait, et l'origine de celle-ci, sont encore inconnus. Chez la chèvre, l'activité LPL du lait tend à évoluer dans le même sens que celle du tissu adipeux, et en sens opposé à celle du tissu mammaire, lorsque varient le stade de lactation et/ou le bilan énergétique, et les animaux étudiés (cf. tab. 7, fig. 16). Deux hypothèses peuvent être avancées pour expliquer ces observations. 
Lot A (6 chèvres).

.... Lot $\mathrm{B}$ (6 chèvres).

- - Lipides protégés.

, ○ Régime témoin.

口, Lipoprotéine-lipase ( $\mu \mathrm{Eq} \quad \mathrm{AGL} / \mathrm{h} / \mathrm{ml})$.

$\circ$, - Lipolyse $(\mu \mathrm{Eq} \mathrm{AGL} / 24 \mathrm{~h} / \mathrm{ml})$.

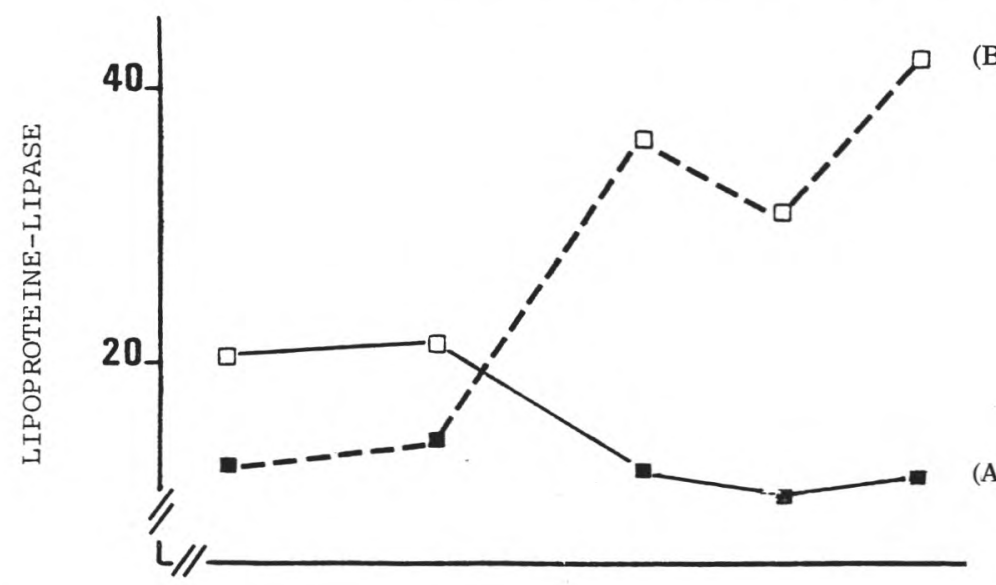

(B)

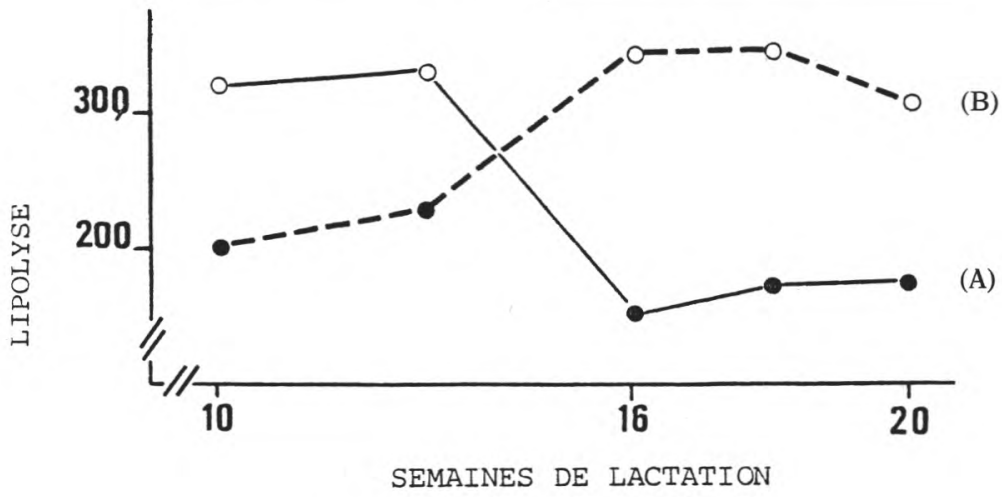

fig. 17

Influence de la distribution de lipides (1) protégés sur la lipolyse et l'activité lipoprotéine-lipasique du lait de chèvre

(Selselet-Attou, Chilliard, Bas et Morand-Fehr, 1981 [224], non publié).

(1) Huile de tournesol.

La LPL du tissu adipeux pourrait parvenir à la mamelle par voie sanguine et être sécrétée dans le lait, comme d'autres protéines sanguines. En effet, Wells et al. [259] ont observé que les variations de l'activité tributyrinasique du lait suivent généralement celles de l'acti- 


\section{TABLEAU 7}

Corrélations entre les activités LPL du tissu mammaire, du tissu adipeux et du lait chez la chèvre en début de lactation

(d'après CHILLIARD et al., 1979)

\begin{tabular}{c|c|c}
\hline & Tissu mammaire & Tissu adipeux \\
\hline Lait & $-0,69(\mathrm{P}<0,02)$ & $+0,60(\mathrm{P}<0,05)$ \\
\hline
\end{tabular}

Onze prélèvements effectués chez 6 chèvres en $3^{\text {e }}$ et $9^{e}$ semaine de lactation. Les activités LPL sont calculées en unités par g de tissu frais ou par ml de lait entier.

vité tributyrinasique du sang. Ceci pourrait expliquer que l'activité LPL du lait soit faible lorsque les animaux sont en bilan énergétique négatif (fig. 12 et 16), c'est-à-dire présentent une faible activité LPL du tissu adipeux.

La seconde hypothèse pourrait être que la LPL du lait provienne des cellules sécrétrices mammaires, où elle serait synthétisée. En effet, le lait fraîchement sécrété, riche en particules cytoplasmiques mammaires, a une forte activité LPL [111] et il en est de même du lait de fin de traite [48]. La lipase, qui agit normalement au niveau des capillaires sanguins, serait d'autant moins disponible pour une "fuite " dans le lait que le tissu mammaire a une plus forte activité LPL, c'est-à-dire est plus actif pour le prélèvement des triglycérides sanguins. Ceci est à rapprocher de l'observation selon laquelle la LPL synthétisée par les cellules mammaires doit normalement " remonter " le flux des protéines du lait en cours de sécrétion, pour migrer vers son site d'action physiologique [184]. D'où une faible activité LPL du lait lorsque les animaux sécrètent beaucoup d'acides gras longs et ont une forte activité LPL mammaire en début de lactation [51] ou lorsqu'ils reçoivent des lipides protégés (fig. 17) ? Par ailleurs, la diminution de l'activité LPL du lait en fin de lactation (cf. § III B.2.a.1 et IV B.2.) pourrait résulter d'une diminution de l'activité LPL globale du tissu mammaire à ce stade [230] ? Une autre observation réalisée chez la lapine plaide en faveur de cette hypothèse. Ainsi, le lait de cette espèce ne contient pas de LPL [198], alors que sa mamelle présente probablement une activité LPL très faible puisqu'elle ne sécrète que très peu d'acides gras longs.

Des investigations plus poussées sont nécessaires pour confirmer ou infirmer ces hypothèses et préciser les mécanismes régulant la sécrétion de la LPL du lait par la mamelle. 


\section{LIPASES ET LIPOLYSE SPONTANEE DANS LE LAIT DE FEMME}

Deux lipases ont été isolées $[119,120]$ à partir du lait de femme :

- une lipoprotéine-lipase, présente dans la phase grasse, ayant une activité généralement inférieure à $150 \mu \mathrm{Eq}$ d'acides gras libérés $/ \mathrm{h} / \mathrm{ml}$;

- une lipase stimulée par les sels biliaires (LSSB), présente dans la phase aqueuse, ayant une activité comprise entre 900 et $5000 \mu \mathrm{Eq}$ $\mathrm{AGL} / \mathrm{h} / \mathrm{ml}[102,42,139,168,41]$.

L'activité LPL et la lipolyse spontanée sont très faibles dans le colostrum, puis augmentent pendant les premières semaines de lactation en particulier pendant la montée laiteuse et chez les femmes ayant un fort pouvoir galactogène. Comme chez les autres espèces, de fortes variations individuelles et journalières sont observées [119, $182,198]$.

L'activité LSSB est très élevée chez tous les individus et à tous les stades de lactation $[119,108]$ avec parfois une tendance à diminuer au cours de la lactation [114, 175].

Les activités des deux lipases semblent dépendre de l'origine ethnique et du statut social des sujets $[118,198]$.

La lipolyse spontanée du lait de femme est due essentiellement à la LPL, malgré la plus faible activité de cette enzyme (tab. 8) [182]

\section{TABLEAU 8}

Corrélations entre les activités lipasiques et la lipolyse spontanée du lait de femme

Lipolyse spontanée

Lipase stimulée par les sels biliaires

Lipoprotéine-lipase

(1) Castberg et Hernell, 1975 (17 femmes, 17 laits).

(2) Luzeau et al., 1975 (13 femmes, 17 laits).

Luzeau et al. [168] font l'hypothèse que la LPL serait le facteur limitant pour l'attaque des globules gras, dans les conditions physicochimiques du lait à $4^{\circ} \mathrm{C}$. La LSSB est quant à elle très peu active dans le lait frais en absence de sels biliaires et joue un rôle mineur dans la lipolyse spontanée [108]. 
Par contre, de nombreuses études montrent que la LSSB joue un rôle non négligeable dans la digestion des lipides par le nouveau-né en allaitement maternel. Contrairement à la LPL, cette enzyme est en effet stable à $37^{\circ} \mathrm{C}$ et au $\mathrm{pH}$ acide de l'estomac, et elle est stimulée par les sels biliaires à son arrivée dans le duodénum de l'enfant [120, 114]. Son activité est suffisante pour hydrolyser tous les triglycérides du lait en 30 min [101].

Les deux lipases (LPL et LSSB) sont détruites par la pasteurisation, mais seule la LPL est détruite par les ultra-violets. Cette propriété rend possible la conservation de laits maternels avec une activité LSSB importante, tout en limitant la lipolyse spontanée. La présence de LSSB dans le lait de femme peut donc avoir une signification importante pour l'alimentation des nouveau-nés (qui présentent une déficience relative en lipase pancréatique) ainsi que pour comparer l'utilisation des lipides des laits humains, animaux et artificiels par ceux-ci.

Castberg et Hernell [41] suggèrent que la LSSB se trouve dans le lait de femme en tant que vraie sécrétion. Son absence chez les mammifères apparus dans l'évolution avant le gorille et l'homme pourrait refléter un processus de sélection naturelle, les gènes codants pour la lipase pancréatique s'exprimant aussi dans les cellules mammaires, chez ces deux espèces seulement [33]. Par contre, la LPL serait un "surplus » du métabolisme mammaire, en accord avec les hypothèses avancées pour la vache et la chèvre.

La localisation de la LPL du lait de femme dans la phase grasse pourrait être liée à la richesse de la membrane des globules gras du lait humain en héparan sulfate, qui en contient environ dix fois plus que chez la vache. Il est par ailleurs intéressant de constater que la membrane des globules gras du colostrum humain est très pauvre en héparan sulfate [229].

\section{AUTRES ESPECES}

La présence d'activités lipasiques a été montrée chez plusieurs autres espèces (tab. 1) mais on n'a pas étudié leur liaison avec le développement de la lipolyse spontanée. Les connaissances sur le lait de brebis sont notamment très faibles.

L'activité lipasique du lait de bufflonne a été étudiée par plusieurs équipes en Afrique et en Asie $[219,128,124,1]$. Sa nature exacte (lipoprotéine-lipase ?) n'a pas été établie. Elle est répartie pour moitié entre les caséines solubles et micellaires. Son activité est comprise entre 30 et $180 \mu \mathrm{Eq}$. AGL $/ \mathrm{h} / \mathrm{ml}$. Elle augmente entre la mise-bas et le $8^{\mathrm{e}}$ mois de lactation et elle diminue au cours de la traite, lorsque l'animal vieillit et lorsqu'il reçoit un régime à base de fourrages verts. 


\section{CONCLUSION}

Les principaux mécanismes et facteurs de variation connus ou supposés de la lipolyse spontanée du lait sont résumés dans le tableau 9. Il apparaît clairement que les connaissances de ce phénomène sont encore très partielles, malgré l'importante somme de travaux qui lui ont été consacrés depuis des décennies. Ceci s'explique en partie par la complexité de cet aspect de la lipolyse, qui est largement dépendant de la physiologie de la mamelle et de l'organisme animal dans son ensemble. Sa compréhension et à terme sa maitrise sont toutefois nécessaires pour contrôler la qualité du lait sécrété et l'effet ultérieur des différents facteurs technologiques (la lipolyse induite étant étroitement liée aux composants du système lipolytique du lait natif) [94].

La clarification de la nature (LPL) de la lipase du lait et l'étude approfondie de ses propriétés ont permis de mieux comprendre les observations antérieures sur la lipase et la lipolyse spontanée. L'action de la LPL dans le lait présente toutefois des caractéristiques propres qui doivent être précisées au niveau biochimique [184].

Contrairement à la LSSB du lait des primates supérieurs qui est probablement un résultat de l'évolution des espèces, la LPL du lait semble être un déchet du métabolisme des triglycérides circulants par la mamelle, permettant dans certaines conditions le développement de la lipolyse. Les mécanismes conduisant à sa sécrétion (synthèse et migration dans les cellules mammaires, origine extramammaire, liaison avec les différents constituants du lait) demandent à être précisés.

Bien que la LPL soit parfois le facteur limitant de la lipolyse spontanée, notamment en début de lactation, elle est généralement présente en excès chez la vache car d'autres composants du système lipolytique limitent son action.

La localisation de la LPL dans la phase aqueuse du lait de vache semble expliquer cette absence de liaison LPL-lipolyse, contrairement à ce qui est observé chez la chèvre et surtout chez la femme (tab. 10). La distribution de la LPL dans le lait des espèces non bovines mériterait d'être mieux connue, afin de préciser le rôle des liaisons LPLmicelles de caséines et LPL-globule gras dans la lipolyse. Il en est de même de la modification éventuelle de cette liaison par les héparinoïdes et les minéraux du lait.

Chez toutes les espèces, l'activité LPL potentielle reste bien supérieure à la lipolyse spontanée ou induite. Ceci résulte de la structure des globules gras (membranes), des conditions physico-chimiques du lait ( $\mathrm{pH}$...) et de la présence d'inhibiteurs, qui freinent l'activité lipasique. Des activateurs peuvent cependant lever en partie ces barrières. La nature et les mécanismes de sécrétion de ces inhibiteurs et activateurs sont encore quasiment inconnus. 


\section{TABLEAU 9}

Principaux mécanismes et facteurs de variation de la lipolyse spontanée du lait Modifications du système lipolytique Facteurs de variation

1. Augmentation de la lipolyse spontanée

- Stabilité du glouble gras $\downarrow$ :

- corps lipidique,

- membrane.

Activateurs lipoprotéiques $\uparrow$ (interaction LPL globules gras).

- Migration de la LPL des micelles de la caséine vers la crème (vache) :

- modification des globules gras,

- héparinoïdes,

— ions ; $\uparrow$ caséines solubles ; protéolyse des caséines.

- $\mathrm{pH}$ du lait $\nearrow$; Km lipase $\downarrow$.

- Lipase des cellules somatiques $\lambda$.
- Acide palmitique ?

- Traite (agitation); refroidissement ; mammites (synthèse ; protéases, phospholipases).

- Sous-alimentation ? Fin de lactation ?

- Fin de lactation ? Faible production laitière? Stress? Acide palmitique ? Régime hypoprotéique? Mammites?

- Refroidissement.

- Oestrus ?

- Mammites.

- Mammites.

2. Diminution de la lipolyse spontanée apparente

Activité LPL $\downarrow$.

Accumulation d'AGL sur les globules gras.

- Estérification des AGL.

- Inhibiteurs $\uparrow$ :

- protéines spécifiques ?

- pH du lait ( $\downarrow$ activité LPL),

- protéines non spécifiques ( $\downarrow$ liaison LPL globules gras).
- Début de lactation; lipides insaturés ? Chez la chèvre, fin de lactation ? Sous-alimentation ? Génotype.

- Absence d'agitation.

- Particules cytoplasmiques. Cellules somatiques ? Forte production laitière ?

- laits normaux ?

- colostrum ? 
TABLEAU 10

Distribution de la LPL du lait et sa corrélation avec la lipolyse spontanée du lait conservé à $4^{\circ} \mathrm{C}$

\begin{tabular}{|c|c|c|}
\hline Espèce & $\begin{array}{c}\text { p. } 100 \text { LPL } \\
\text { dans la crème }\end{array}$ & $\begin{array}{l}\text { Corrélation } \\
\text { lipolyse-LPL }\end{array}$ \\
\hline Femme & $92(1)$ & $0,9(2)$ \\
\hline Chèvre & $45(3,4)$ & 0,65 à $0,8(3,4)$ \\
\hline Vache & 5 à $30(4,5)$ & faible (6) \\
\hline \multicolumn{3}{|c|}{ (1) Hernell et Olivecrona, $1974 \mathrm{a}}$. \\
\hline \multicolumn{3}{|c|}{, 1975 ; LuZEAU } \\
\hline \multicolumn{3}{|c|}{ CASTBERC } \\
\hline \multicolumn{3}{|l|}{ (4) Selselet-Attou, } \\
\hline \multicolumn{3}{|l|}{ (5) Voir le $\S$ III $A$} \\
\hline \multicolumn{3}{|c|}{ (6) Voir le $\S$ III $A_{1}$. } \\
\hline
\end{tabular}

Les investigations sur les facteurs de variation physiologiques et zootechniques de la lipolyse spontanée ont souvent donné lieu à des résultats contradictoires. Ceci peut s'expliquer à la fois par les importantes variations individuelles et journalières du phénomène et la difficulté de faire la part des différents facteurs (stades de lactation et de gestation, activité sexuelle, niveau de production laitière, quantité et qualité des aliments ingérés, transitions alimentaires, intervalles de traite, état sanitaire de la mamelle, saison, durée des expérimentations). Si l'on ajoute que la plupart du temps seuls quelques composants du système lipolytique ont été pris en compte, on comprend mieux la fragilité des connaissances suggérée par le tableau 9. Des études systématiques, fondamentales et appliquées, menées par des équipes pluridisciplinaires et chez plusieurs espèces animales sont nécessaires pour y remédier.

Dans l'état actuel des connaissances, il est possible de préconiser certaines mesures pratiques permettant de mieux maîtriser la lipolyse spontanée du lait :

- sélection des animaux (notamment chez les caprins);

- étalement des mises-bas chez les bovins (fins de lactation) ;

- tarissement rapide des vaches faibles productrices (moins de $5 \mathrm{~kg}$ de lait par jour) ;

- alimentation selon les besoins des animaux, en particulier chez la vache en fin de lactation ; distribution de fourrages de qua- 
lité ; éviter les suppléments très riches en acide palmitique et les changements brutaux de régime ;

- prévention des mammites, éviter en particulier la surtraite (passage d'éléments sanguins) ; élimination des laits mammiteux ;

- thermisation ou traitement du lait aux ultra-violets.

Le cas du lait de chèvre pourra se raisonner différemment en raison des particularités de son système lipolytique, et du niveau de lipolyse souhaitable pour une qualité optimale du lait et du fromage.

$$
\text { 承 }
$$

\section{ERRATUM}

Première partie «Le Lait », vol. 62, p. 19, 22e ligne, lire " jouent effectivement un rôle dans la lipolyse, soit par leur lipase, soit par leur... ».

$$
\text { 橡 }
$$

Les travaux de l'auteur sur la lipoprotéine-lipase et la lipolyse dr. dait de chèvre ont été réalisés au Laboratoire de Recherches de la Chaire de Zuutechnie (I.N.R.A.) de I'Institut National Agronomique Paris-Grignon (16, rue ClaudeBernard - 75005 Paris), en collaboration avec G. Selselet-Attou, P. Bas et P. Morand-Fehr.

$$
\text { 草* }
$$

\section{Résumé}

La nature et les propriétés biochimiques de la lipase du lait (lipoprotéine-lipase) sont examinées dans la première partie de cette revue, en liaison avec le rôle physiologique et le mode d'action de cette enzyme dans les tissus animaux. Dans la seconde partie, les composants du système lipolytique du lait impliqués dans la lipolyse spontanée sont définis (membrane des globules gras du lait ; distribution de la lipase entre les phases lipidique, aqueuse et caséique ; activateurs polypeptiques et héparinoïdes ; accepteurs d'acides gras libres ; protéines inhibitrices spécifiques ou non spécifiques; activité lipogénique du lait; cellules somatiques). La troisième partie est consacrée aux variations physiologiques de l'activité lipasique et de la lipolyse spontanée dans le lait de vache (variations individuelles et à court terme ; stades de lactation et de gestation; œstrus ; niveau alimentaire et nature du régime ; mammites) et à leurs relations avec les composants du système lipolytique. La quatrième partie traite des travaux récents effectués en Norvège et en France sur la lipoprotéine-lipase et la lipolyse spontanée du lait de chèvre. La dernière partie se rapporte aux activités lipasiques et à la lipolyse dans le lait de femme et, dans une moindre mesure, à l'activité lipasique du lait de buflonne. Cette étude fait ressortir la nécessité de nouvelles recherches sur la lipolyse spontanée, ayant un caractère systématique et pluridisciplinaire et conduites parallèlement sur plusieurs espèces animales. Quelques recommandations pratiques en 
vue de mieux contrôler la lipolyse spontanée du lait sont aussi rappelées.

\section{S u m m a ry}

\section{PHYSIOLOGICAL VARIATIONS IN LIPASE ACTIVITIES AND SPONTANEOUS LYPOLYSIS IN BOVINE, CAPRINE AND HUMAN MILK: A REVIEW}

In the first part of this paper, the nature and biochemical properties of the milk lipase (lipoprotein lipase) are reviewed together with the physiological role and type of activity of this enzyme has in various animal tissues. In the second part, components of the "lipolytic system» in cow milk are defined in relation with spontaneous lipolysis (milk fat globule membrane; lipase distribution between lipid, aqueous and particulate phases; polypeptidic and heparinlike activators; free fatty acid acceptors; specific and non-specific inhibitor proteins; milk lipogenic activity; somatic cells). The third part deals with physiological variations in lipase activity and spontaneous lipolysis in cow milk (short-term and individual variations; different stages of lactation and pregnancy; œstrus; level and type of feeding; mastitis) and their relationships to lipolytic system components. In the fourth part, recent Norwegian and French studies on lipoprotein lipase and spontaneous lipolysis in goat milk are reviewed. The last part deals with lipase activities and fat lipolysis in human milk and, to a lesser extent, with buffalo milk lipase. Further systematic, pluridisciplinary investigations on spontaneous lipolysis in different species are called for. Some practical recommendations to control lipolysis are given.

\section{Bibliographie}

[1] Abdel-Hamid (L. B.), Mahran (G. A.) Shehata (A. E.) and Osman (S. G.) (1977). - Egyptian J. Dairy Sci., 5, 7.

[2] Ali (A. E.), Andrews (A. T.) and Cheeseman (G. C.), (1980 a). - J. Dairy Res., 47, 371.

[3] Ali (A. E.), Andrews (A. T.) and Cheeseman (G. C.) (1980 b). - J. Dairy Res., 47, 393.

[4] Anderson (M.) (1977). - J. Dairy Sci., 60, 1217.

[5] Anderson (M.) (1979), - J. Dairy Sci., 62, 1380.

[6] Anderson (M.) (1981). - J. Dairy Res., 48, 247.

[7] Anderson (M.) and Andrews (A. T.) (1977). - J. Dairy Res., 44, 223.

[8] Anderson (M.) and Cawston (T. E.) (1975). - J. Dairy Res., 42, 459.

[9] Anderson (M.) et Cheeseman (G. C.) (1975), - Bull. Féd. Int. Laiterie, Doc. $86,11$.

[10] AnNison (E. F.), BickerstafFe (R.) and Linzell (J. L.) (1974). - J. agric. Sci., 82, 87.

[11] Asher (Y. J.) (1980). - Dissert. Abstr. Int., 40, 5190-B.

[12] Askew (E. W.), Emery (R.S.) and Thomas (J. W.) (1970). - J. Dairy Sci., $53,1415$. 
[13] Astrup (H. N.), Baevre (L.), Vik-Mo (L.) and Ekern (A.) (1980 a). - J. Dairy Res., 47, 287.

[14] Astrup (H. N.), Skrøvseth (O.), Vik-Mo (L.), Ekern (A.) und Sola (E.) (1977). - Meieriposten, 66, 681.

[15] Astrup (H. N.), Vik-Mo (L.), Lindstad (P.) und EkeRn (A.) (1979). - Milchwissenschaft, 34, 290.

[16] Astrup (H. N.), Vik-Mo (L.), Skrøvseth (O.) und Ekern (A.) (1980 b). Milchwissenschaft, 35, 1.

[17] Bachman (K. C.) and Guller (S. M.) (1980). - J. Dairy Sci., 63, Supplt. 1, 161.

[18] Bachman (K. C.) and Wilcox (C. J.) (1977). - J. Dairy Sci., 60, Supplt. 1, 61.

[19] Bakke (H.), Steine (T.) and EgGum (A.) (1977). - Acta Agric. Scand, 27, 245.

[20] Barky (J. C.) and Donnelly (W. J.) (1980). - J. Dairy Res., 47, 71.

[21] BarRy (J. M.), Bartley (W.), Linzell (J. L.) and Robinson (D. S.) (1963). Biochem. J., 89, 6.

[22] Barky (J. M.) and Rowland (S. J.) (1953). - Biochem. J., 54, 575.

[23] Bas (P.), Morand-Fehr (P.) and Rouzeau (A.) (1978). - 20th Int. Dairy Congr., Vol. E, 301.

[24] Bengtsson (G.) and Olivecrona (T.) (1977). - Eur. J. Biochem., 79, 225.

[25] Bengtsson (G.) and Olivecrona (T.) (1980 a). - Eur. J. Biochem., 106, 549.

[26] Bengtsson (G.) and Olivecrona (T.) (1980 b). - Eur. J. Biochem., 106, 557.

[27] Bengtsson (G.) and Olivecrona (T.) (1981), - Eur. J. Biochem., 113, 547.

[28] Benson (J. D.), Askew (E. W.), Emery (R. S.) and Thomas (J. W.) (1972). J. Dairy Sci., 55, 83.

[29] Bergman (E. N.), Havel (R. J.), Wolfe (B. M.) and Bohmer (T.) (1970). Fed. Proc., 29, 327.

[30] Bettenay (R. A.) (1978). - Austr. J. Dairy Technol., 33, 13.

[3i] Bhattacharya (A. N.) (1980), - J. Dairy Sci., 63, 1981.

[32] BJöRKE (K.) and CASTBERG (H. B.) (1976). - North European Dairy J., 8, 296.

[33] Blackberg (L.), Hernell (O.), Olivecrona (T.), Domellöf (L.) and Malinov (M. R.) (1980). - FEBS Lett., 112, 51.

[34] Borges (M. S.) (1975). - Diss. Abstr. Int., 35, 4733-B.

[35] BRooker (B. E.) (1978). - J. Dairy Res., 45, 21.

[36] Brown (W. V.) and Baginski (M. L.) (1972). - Biochem. Biophys. Res. Comm., 46, 375.

[37] Brumby (P. E.) (1971). - Nat. Inst. Res. Dairying. Report 1969-70, 121.

[38] Campbell (M. H.) (1932), - Cité par Mulder et Walstra (1974).

[39] Cannon (R. Y.) and Rollins (G. H.) (1964). - J. Dairy Sci., 47, 41.

[40] Castberg (H. B.), Egelrud (T.), Solberg (P.) and Olivecrona (T.) (1975). J. Dairy Res., 42, 255.

[41] Castberg (H. B.) und Hernell (O.) (1975). - Michwissenschaft, 30, 721.

[42] Castberg (H. B.) und Solberg (P.) (1972). - Meieriposten, 61 (34-35), 683.

[43] Castberg (H. B.) und Solberg (P.) (1974). - Meieriposten, 63 (51-52), 961.

[44] Chandan (R. C.), Parry (R. M. Jr) and Shahani (K. M.) (1968). - J. Dairy Sci., 51, 606.

[45] Childs (M. T.), Tollefson (J.), Knopp (R. H.) and Bowden (D. A.) (1981). Metabolism, 30, 27.

[46] Chilliard (Y.) et Fehr (P. M.) (1976 a). - Ann. Technol. agric., 25, 219.

[47] Chilliard (Y.) et Fehr (P. M.) (1976 b). - Ann. Technol. agric., 25, 231. 
[48] Chilliard (Y.) et Morand-Fehr (P.) (1978 a). - Le Lait, 58, 1.

[49] Chilliard (Y.) and Morand-Fehr (P.) (1978 b). - 20th Int. Dairy Congr., Vol. E, 302.

[50] Chilliard (Y.), Sauvant (D.), Hervieu (J.), Dorléans (M.) et Morand-Fehr (P.) (1977). - Ann. Biol. anim. Bioch. Biophys., 17, 1021.

[51] Chilliard (Y.), Sauvant (D.), Morand-Fehr (P.) et Durand (G.) (1978 a). C.R. Acad. Sci., Paris, Sér. D., 287, 871.

[52] Chilliard (Y.), Durand (G.), Sauvant (D.) et Morand-Fehr (P.) (1978 b). C.R. Acad. Sci., Paris, Sér. D., 287, 1131.

[53] Chilliard (Y.), Sauvant (D.) et Morand-Fehr (P.) (1979). - Ann. Rech. Vét., 10, 404.

[54] Christie (W. W.) (1974)。 - Lipids, 9, 876.

[55] Christie (W. W.) (1977). - J. Dairy Sci., 60, 1433.

[56] Clegg (R. A.) (1978). - Biochem. Soc. Trans., 6, 1207.

[57] Clegg (R. A.) (1979). - Biochem. Soc. Trans., 7, 1053.

[58] Clegg (R. A.) (1980). - J. Dairy Res., 47, 61.

[59] Clegg (R. A.) (1981). - Biochim. Biophys. Acta, 663, 598.

[60] Connoly (J. F.) (1978). - 20th Int. Dairy Congr. Doc. 62 ST (B.).

[61] Connoly (J. F.), Murphy (J. J.), O'Connor (C. B.) et Headon (D. R.) (1980). Bull. Féd. Int. Laiterie, Doc. 118, 67.

[62] Decaen (C.) et Ghadaki (M. B.) (1970). - Ann. Zootech., 19, 399.

[63] DeEth (H. C.) (1978). - 20th Int. Dairy Congr., Vol. E, 364.

[64] Deeth (H. C.) et Fitz-Gerald (C. H.) (1975). - Bull. Féd. Int. Laiterie, Doc. $86,24$.

[65] Deeth (H. C.) and Fitz-Gerald (C. H.) (1976). - Aust. J. Dairy Technol., $31,53$.

[66] Deeth (H. C.) and Fitz-Gerald (C. H.) (1977). - J. Dairy Res., 44, 569.

[67] Deeth (H. C.) and Fitz-Gerald (C. H.) (1978). - 20th Int. Dairy Congr., Vol. E, 308.

[68] De Gasquet (P.), Griglio (S.), Péouignot-Planche (E.) et Malewiak (M. I.) (1977). - J. Nutr., 107, 199.

[69] Delouis (C.) (1978). - Ann. Rech. Vét., 9, 193.

[70] Devendra (C.) (1980). - J. Dairy Sci., 63, 1755.

[71] Dils (R.), Clark (S.) and Knudsen (J.) (1977). - In Peaker (M.) « Comparatives aspects of lactation ". Symp. Zool. Soc. London, 41, 43.

[72] Dimarco (N. M.), Beitz (D. C.) et Whitehurst (G. B.) (1981). - J. Anim. Sci., 52, 75.

[73] Doize (F.) et Paquay (R.) (1980). - Arch. Int. Physiol. Biochim., 88, 18.

[74] Dowben (R. M.), Brunner (J. R.) and Philpott (D. E.) (1967). - Biochim. Biophys. Acta, 135, 1.

[75] Downey (W. K.) (1975). - Bull. Féd. Int. Laiterie, Doc. 86, 80.

[76] Downey (W. K.) (1980). - Bull. Féd. Int. Laiterie, Doc. 118, 4.

[77] Downey (W. K.) and Murphy (R. F.) (1970 a). - J. Dairy Res., 37, 47.

[78] Downey (W. K.) and Murphy (R. F.) (1970 b). - J. Dairy Res., 37, 361.

[79] Downey (W. K.) et Murphy (R. F.) (1975). - Bull. Féd. Int. Laiterie, Doc. 86, 19.

[80] Driessen (F. M.) (1976). - Neth. Milk Dairy J., 30, 186.

[81] Driessen (F. M.) and Stadhouders (J.) (1974). - Neth. Milk Dairy J., 28, 130.

[82] Driessen (F. M.) et Stadhouders (J.) (1975). - Bull. Féd. Int. Laiterie, Doc. $86,73$. 
[83] Dunkley (W. L.) and Smith (L. M.) (1951 a). - J. Dairy Sci., 34, 935.

[84] DunkLey (W. L.) and Smith (L. M.) (1951 b). - J. Dairy Sci., 34, 940.

[85] Durand (G.) et Penot (E.) (1978). - Ann. Nutr. Alim., 32, 1217.

[86] Egelrud (T.) and Olivecrona (T.) (1972). - J. Biol. Chem., 247, 6212.

[87] Egelrud (T.) and Oltvecrona (T.) (1973). - Biochim. Biophys. Acta, 306, 115.

[88] Eisenberg (S.), Schurr (D.), Goldman (H.) and Olivecrona (T.) (1978). Biochim. Biophys. Acta, 531, 344.

[89] EMERY (R. S.) (1973). - J. Dairy Sci., 56, 1187.

[90] Ermose (C.) and Pedersen (K.L.) (1978). - 20th Int. Dairy Congr., Vol. E, 29.

[91] ERwin (R. E.) and Randolph (M. E.) (1975). - J. Dairy Sci., 58, 9.

[92] Fédération Internationale de Laiterie (1974), - Bull. Ann., Doc. 82, 40 p.

[93] Fédération Internationale de Laiterie (1975). - Bull. Ann., Doc. 86, 197 p.

[94] Fédération Internationale de Laiterie (1980). - Bull. Ann., Doc. 118, 76 p.

[95] Fielding (C. J.) and Fielding (P. E.) (1976), - J. Lipid Res., 17, 248.

[96] Fitz-Gerald (C. H.), Deeth (H. C.) and Kitchen (B. J.) (1981). - J. Dairy Res., 48, 253.

[97] Fleming (M. G.) (1980). - Bull. Féd. Int. Laiterie, Doc. 118, 41.

[98] Forster (T. L.), Montgomery (M. W.) and Montoure (J. E.) (1961). - J. Dairy Sci., 44, 1420.

[99] Fox (P. F.), Yaguchi (M.) and Tarassuk (M. P.) (1967). - I. Dairy Sci., 50, 307.

[100] Fredeen (H.), Bowstead (J. E.), Dunkley (W. L.) and Smith (L. M.) (1951). J. Dairy Sci., 34, 521.

[101] Frederickzon (F.), Hernell (O.), Blackberg (L.) and Olivecrona (T.) (1978). - Pediatr. Res., 12, 1048.

[102] Freudenberg (E.) (1953). - Die Frauenmilch-lipase (Karger J., Ed., Bâle, Suisse).

[103] FReUdENBERg (E.) (1966). - Experientia, 22, 317.

[104] Gaffeney (P. J.) and Harper (W. J.) (1965). - J. Dairy Sci., 48, 613.

[105] Gholson (J. H.), Schexnatlder (R. H.) and Rusoff (L. L.) (1966). - J. Dairy Sci., 49, 1136.

[106] Goubern (M.) and Portet (R.) (1981). - Horm. Metab. Res., 13, 73.

[107] Guthrie (E. S.) and Herrington (B. L.) (1960). - J. Dairy Sci., 43, 843.

[108] Hall (B.), Muller (D. P. R.) and Harries (J. T.) (1979). - Proc. Nutr. Soc., 38, 114 A.

[109] Hamosh (M.), Clary (J. R.), Chernick (S. S.) and Scow (R. O.) (1970), Biochim. Biophys. Acta, 210, 473.

[110] Hamosh (M.) and Scow (R. O.) (1971). - Biochim. Biophys. Acta, 231, 283.

[111] Hannah Research Institute (1976). - Report, p. 32.

[112] Harper (W. J.), Gould (I. A.) and Badami (M.) (1956), - J. Dairy Sci., 39, 910.

[113] Haugeback (C. D.), Hedrick (H. B.) and Asplund (J. M.) (1974). - J. Anim. Sci., 39, 1026.

[114] Hayasawa (H.), Kiyosawa (I.) et Nagasawa (T.) (1974). - 19e Congr. Int. Laiterie, $1 F, 610$.

[115] Hemingway (E. B.), Smith (G. H.), Rook (J.A. F.) and O'Flanagan (N. C.) (1970). - J. Soc. Dairy Technol., 23, 44.

[116] Henningson (R. W.) (1964). - J. Dairy Sci., 47, 337.

[117] Hernell (O.), Egelrud (T.) and Olivecrona (T.) (1975). - Biochim. Biophys. Acta, 381, 233.

[118] Hernell (O.), Gebre-Medhin (M.) and Olivecrona (T.) (1977). - Am. J. Clin. Nutr., 30, 508. 
[119] Hernell (O.) and Olivecrona (T.) (1974 a). - J. Lipid Res., 15, 367.

[120] Hernell (O.) and Olivecrona (T.) (1974 b). - Biochim. Biophys. Acta, $369,234$.

[121] Herrington (B. L.) (1954). - J. Dairy Sci., 37, 775.

[122] Herrington (B. L.) and Krukovsky (V. N.) (1939). - J. Dairy Sci., 22, 149.

[123] Hileman (J. L.) and Courtney (E.) (1935). - J. Dairy Sci., 18, 247.

[124] Hofi (A. A.), Mahran (G. A.), Abdel-Hamid (L. B.) and Osman (S. G.) (1976). - Egyptian J. Dairy Sci., 4, 111.

[125] Homer (D. R.) und Virtanen (A. I.) (1968). - Milchwissenschaft, 23, 163.

[126] Hoynes (M. C. T.) and Downey (W. K.) (1973). - Biochem. Soc. Trans., $1,256$.

[127] Hunter (A. C.), Wilson (J. M.) and Greig (G. W.) (1968). - J. Soc. Dairy Technol., 21, 139.

[128] Ismail (A. A.), RifaAt (I. D.), AbD-el-Aal (A. T.) and El-SadeK (G. M.) (1975). - Egyptian J. Dairy Sci., 3, 6.

[129] Iverius (P. H.), Lindahl (U.), Egelrud (T.) and Olivecrona (T.) (1972). J. Biol. Chem., 247, 6610 .

[130] Iverius (P. H.) and Oestlund-Lindovist (A. M.) (1976). - J. Biol. Chem., $251,7791$.

[131] Jackson (R. L.), Pattus (F.) and DE HaAs (G.) (1980). - Biochemistry, 19,373 .

[132] Jellema (A.) (1975), - Neth. Mitk Dairy J., 29, 145.

[133] Jellema (A.) (1980). - Bull. Féd. Int. Laiterie, Doc. 118, 33.

[134] Jellema (A.) et Schipper (C. J.) (1975). - Bull. Féd. Int. Laiterie, Doc. $86,2$.

[135] Jenness (R.) (1980). - J. Dairy Sci., 63, 1605.

[136] JENNY (B.) (1974), - Interrelationship of milk fat secretion with ruminal volatile fatty acids and serum insulin and glucose. Ph. D. Thesis, Virginia State Univ. U.S.A.

[137] Jensen (R. G.) (1959). - J. Dairy Sci., 42, 1619.

[138] Jensen (R. G.) (1964), - J. Dairy Sci., 47, 210.

[139] Jubelin (J.) and Boyer (J.) (1972). - Europ. J. Clin. Invest., 2, 417.

[140] JuRCZAK (M. E.) und ScIUbisz (A.) (1981). - Milchwissenschaft, 36, 217.

[141] Kannan (A.) and Basu (K. D.) (1951). - Indian J. Dairy Sci., 4, 63.

[142] Kastli (P.) (1973). - Wien. tierärztl. Mschr., 60, 43.

[143] Keenan (T. W.), Franke (W. W.), Mather (I. H.) and Morre (D. J.) (1978). In LARSON (B. L.) "Lactation, a comprehensive treatise». Vol. 4, 405, Acad. Press, N. Y.

[144] Keenan (T.W.), Morre (D.J.) and Huang (C.M.) (1974). - In Larson (B.L.) and SмITH (V. R.) "Lactation, a comprehensive treatise». Vol. 2, 191, Acad. Press, N. Y.

[145] Kelly (P. L.) (1945). - J. Dairy Sci., 28, 803.

[146] Kinnunen (P. K. J.), Jackson (R. L.), Smith (L. C.), Gotto (A. M. Jr) and Sparrow (J. T.) (1977), - Proc. Natl. Acad. Sci. U.S.A., 74, 4848.

[147] Kitchen (B. J.) (1981). - J. Dairy Res., 48, 167.

[148] Kogev (A.) et Ratchev (R.) (1970). - 18 Congr. Int. Laiterie, 1 F, 204.

[149] KoRn (E. D.) (1959). - Methods Biochem. Anal., 7, 145.

[150] Korn (E. D.) (1962). - J. Lipid Res., 3, 246.

[151] Kuzbzal-Savoie (S.) (1975). - Bull. Féd. Int. Laiterie, Doc. 86, 165.

[152] Kuzdzal-Savoie (S.) (1980 a). - Bull. Féd. Int. Laiterie, Doc. 118, 53. 
[153] Kuzdzal-Savoie (S.) (1980 b). - La lipolyse dans les crèmes et les beurres. Conférence aux journées du C.E.P.I.L., $12-13$ mars , 43 p.

[154] Kuzdzal-Savoie (S.) and Kuzdzal (W.) (1962). - 16th Int. Dairy Congr., Vol. A., 270.

[155] Kuzdzal-Savoie (S.) et Mocouot (G.) (1960). - Ann. Technol. Agric., 9, 5.

[156] La Rosa (J. C.), Levy (R. I.), Herbert (P. N.), LuX (S. E.) and Fredrickson (D. S.) (1970). - Biochem. Biophys. Res. Commun., 41, 57.

[157] Lee (C. S.), Wooding (F. B. P.) and Kemp (P.) (1980). - J. Dairy Res., 47, 39.

[158] Le Jaouen (J. C.) et Le Mens (P.) (1978). - 2e Symp. Int. sur la traite mécanique des petits ruminants, 54 .

[159] LIM (C. T.) and SCANU (A. M.) (1976). - Artery, 2, 483.

[160] Lin (R. H.) and RandolPh (H. E.) (1977). - J. Dairy Sci, 60, Supplt. 1, 44.

[161] Linzell (J. L.) (1974). - In Larson (B. L.) and SMith (V. R.). «Lactation, a Comprehensive treatise», Vol. 1, 143, Acad. Press, N.Y.

[162] Linzell (J. L.) and PeAKer (M.) (1972), - Br. Vet. J., 128, 284.

[163] Long (C. A.) and Patton (S.) (1978), - J. Dairy Sci., 61, 1392.

[164] LunaAs (T.) (1960). - Acta chem. scand., 14, 773.

[165] Luthala (A.) und Antila (M.) (1968), - Fette Seifen Anstrichm., 70, 280.

[166] Luthala (A.), Koskinen (E. H.) et Antila (M.) (1970 a). - 18 Congr. Int. Laiterie, $1 F, 82$.

[167] Luthala (A.), Korhonen (H.), Koskinen (E. H.) et Antila (M.) (1970 b). $18^{\circ}$ Congr. Int. Laiterie, $l F, 83$.

[168] Luzeau (R.), Odièvre (M.), Levillain (P.) et Lemonnier (A.) (1975). - Clin. Chim. Acta, 59, 133.

[169] Lythgoe (H. C.) and Rosenthal (A. S.) (1942). - Cités par Parkash (S.) et JeNneSs (R.) (1968). - Dairy Sci. Abstr., 30, 67.

[170] Mc Bride (O. W.) and Korn (E. D.) (1963). - J. Lipid Res., 4, 17.

[171] Mc CaRthy (R. D.) and Patton (S.) (1964). - Nature, 202, 347.

[172] Mahieu (H.) (1979). - In Inst. Tech. Elev. Bovin, "Annuel de l'Eleveur bovin ", 133 .

[173] Matrick (E. C. V.) and Kay (H. D.) (1938). J. Dairy Res., 9, 58.

[174] Menger (J. W.) (1975). - Bull. Féd. Int. Laiterie, Doc. 86, 108.

[175] Mirzakarimov (U. M.) (1974). - Cité in Dairy Sci. Abstr., 1975, 37, 8120.

[176] Morand-Fehr (P.) Bas (P.) et Sauvant (D.) (1981), - In I.N.R.A.-I.T.O.V.I.C. "Nutrition et systèmes d'alimentation de la chèvre ", vol. 2, 28 .

[177] Morley (N.) and Kuksis (A.) (1977). - Biochim. Biophys. Acta, 487, 332.

[178] Morley (N. H.), KuKsis (A.) and BuchneA (D.) (1974). - Lipids, 9, 481.

[179] Mulder (H.) and Walstra (P.) (1974). - «The milk fat globule». C.A.B., Farnham Royal, Bucks, Angleterre, 296 p.

[180] Newbould (F. H. S.) (1974). - In Larson (B. L.) and Smith (V. R.) «Lactation, a comprehensive treatise», Vol, 2, 269, Acad. Press, N. Y.

[181] Nilsson-Ehle (P.), Egelrud (T.), Belfrage (P.), Olivecrona (T.) and BorgSTRöm (B.) (1973). - J. Biol. Chem., 248, 6734.

[182] Odièvre (M.) and Luzeau (R.) (1978). - Acta Paediatr. Scand., 67, 49.

[183] Okumura (S.), Iwai (M.) and Tsujisaka (Y.) (1981). - Agric. Biol. Chem., $45,185$.

[184] Olivecrona (T.) (1980). - Bull. Féd. Int. Laiterie, Doc. 118, 19.

[185] Olivecrona (T.), Bengtsson (G.), Marklund (S. E.), Lindahl (U.) and HööK (M.) (1977). - Fed. Proc., 36, 60. 
[186] Olivecrona (T.), Egelrud (T.), Hernell (O.), Castberg (H.) et Solberg (P.) (1975). - Bull. Féd. Int. Laiterie, Doc. 86, 61.

[187] Olivecrona (T.) and Lindahl (U.) (1969). - Acta Chem. Scand., 23, 3587.

[188] Ortiz (M. J.), Kesler (E. M.), Watrous (G. H.) and Cloninger (W. H.) (1970). - J. Milk Fd. Technol., 33, 339.

[189] OstLund-Lindevist (A. M.) and Iverius (P. H.) (1975). - Biochem. Biophys. Res. Comm., 65, 1447.

[190] Otway (S.) and Robinson (D. S.) (1968), - Biochem. J., 106, 677.

[191] PaApe (M. J.) and TUcker (H. A.) (1966). - J. Dairy Sci., 49, 265.

[192] PALMER (L. S.) (1922), - J. Dairy Sci., 5, 201.

[193] Palmouist (D. L.) (1976). - J. Dairy Sci., 59, 355.

[194] Patton (S.) and Keenan (T. W.) (1975). - Biochim. Biophys. Acta, 415, 273.

[195] Peereboom (J. W. C.) (1969). - Fette Seifen Anstrichm., 71, 314.

[196] Peterson (M. H.), Johnson (M. J.) and Price (W. V.) (1943). - J. Dairy Sci, 26, 233.

[197] Philippy (B. Q.) and Mc Carthy (R. D.) (1979). - Biochim. Biophys. Acta, 584, 298.

[198] Picandet (B.), Etienne (J.), Barrat (J.) et Polonovski (J.) (1980). - J. Gyn. Obst. Biol. Repr., 9, 331.

[199] Powell (J. T.), Jarlfors (U.) and Brew (K.) (1977). - J. Cell Biol., 72, 617.

[200] Puppione (D. L.) (1978). - J. Dairy Sci., 61, 651.

[201] Purnell (D. M.) and Combs (J. W.) (1973). - Life Sci., 12, 253.

[202] Radomski (M. W.) and Orme (T.) (1971). - Am. J. Physiol., 220, 1852.

[203] Randolph (H. E.) and Erwin (R. E.) (1974). - J. Dairy Sci., 57, 865.

[204] Randolph (H. E.), Parker (R. D.) and Lane (G. T.) (1977). - J. Dairy Sci., 60, Supplt. 1, 57.

[205] Rao (D. R.), Hawkins (G. E.) and Sмith (R. C.) (1973). - J. Dairy Sci., $56,1415$.

[206] RapP (D.) and Olivecrona (T.) (1978) + - Eur. J. Biochem., 91, 379.

[207] Rault (C.), Fruchart (J. C.), Dewailly (P.), Jaillard (J.) and Sezille (G.) (1974). - Biochem. Biophys. Res. Comm., 59, 160.

[208] Renner (E.) and Shahin (Y.) (1978), - 20th Int. Dairy Congr., Vol. E., 274.

[209] Ribadeau-Dumas (B.) (1979). - Rev, Lait. Fr., 371, 15 p.

[210] Roahen (D. C.) and Sommer (H. H.) (1940). - J. Dairy Sci., 23, 831.

[211] Robinson (D. S.) (1963). - Adv. Lipid. Res., 1, 133.

[212] Robinson (D. S.) (1970). - Compr. Biochem., 18, 51.

[213] Rose (D.) (1968). - J. Dairy Sci., 51, 1897.

[214] Saito (Z.), Kitaya (E.) and Okazaki (M.) (1978). - Bull. Fac, Agric. Hirosaki Univ., 29, 77.

[215] Salih (A.M. A.) and Anderson (M.) (1978 a). - Nat. Inst. Res. Dairying. Report 1977-78, 116.

[216] Salih (A.M.A.) and Anderson (M.) (1978 b). - J. Dairy Sci., 61, Supplt. 1, 117.

[217] SAlih (A. M. A.) and Anderson (M.) (1979 a). - J. Dairy Res., 46, 623.

[218] Salih (A. M. A.) and Anderson (M.) (1979 b). - J. Dairy Res., 46, 453.

[219] Sammanwar (R. S.) et Ganguli (N. C.) (1974). - 19e Congr. Int. Laiterie, Vol. 1 F, 380.

[220] Schultz (L. H.) (1977). - J. Food. Prot., 40, 125.

[221] Scow (R. O.), Blanchette-Mackie (E. J.) and Smith (L. C.) (1976). - Circ. Res., 39, 149.

[222] Scow (R. O.) and Egelrud (T.) (1976). - Biochim. Biophys. Acta, 431, 538. 
[223] Scow (R. O.) and Olivecrona (T.) (1977). - Biochim Biophys. Acta, 487, 472.

[224] Selselet-Attou (G.), Chilliard (Y.), Bas (P.) et Morand-Fehr (P.) (1980 et 1981). - Résultats non publiés.

[225] Shahani (K. M.) and Chandan (R. C.) (1965). - Arch. Biochem. Biophys., 111, 257.

[226] Shahant (K. M.), Khan (I. M.) and Chandan (R. C.) (1976). - J. Dairy Sci., $59,369$.

[227] Shahin (Y.) (1977). - Thèse citée in Dairy Sci. Abstr., 40, (1978), 4258.

[228] Sharma (K. K) and Randolph (H. E.) (1974). - J. Dairy Sci., 57, 19.

[229] Shimizu (M.), Uryu (N.) and Yamauchi (K.) (1981). - Agric. Biol. Chem., 45, 741.

[230] SHIRLEY (J. E.) (1973). - Regulatory aspects of triglyceride up-take by bovine adipose and mammary tissues. Ph. D. Thesis; Michigan State Univ. East Lansing, U.S.A.

[231] Shirley (J. E.), EMery (R. S.), Convey (E. M.) and OXender (W. D.) (1973), J. Dairy Sci., 56, 569.

[232] Singh (L. N.) and Ganguli (N. C.) (1975), - Indian J. Dairy Sci, $28,67$.

[233] Singh (L. P.), Yadava (R. K.) and Rawat (R. S.) (1977). - Indian J. Anim. Sci., 47, 328.

[234] SkJevdal (T.) (1979). - Livest. Prod. Sci., 6, 397.

[235] Sleigh (R. W.), Bain (J. M.) and Burley (R. W.) (1976). - J. Dairy Res., 43, 389.

[236] Stead (D.), Tamir (M.) and Welch (V. A.) (1978). - J. Dairy Sci, 61, 1529.

[237] Stead (D.) and Welch (V. A.) (1976). - J. Dairy Sci., 59, 1.

[238] Steine (T. A.) (1978). - E.A.A.P., 29th Annual meeting. Doc. 1-10, 6 p.

[239] Stobis (T. H.), Deeth (H. C.) and Fitz-Gerald (C. H.) (1973). - Austr. J. Dairy Technol., 28, 170.

[240] Storky (J. E.), Brumby (P. E.) et Dunkiey (W. L.) (1980). - Bull. Féd. Int. Laiterie, Doc. 125, 105.

[241] Storry (J. E.), BRumby (P. E.), Hall (A. J.) and Johnson (V. W.) (1974). J. Dairy Res., 41, 165.

[242] Suhren (G.), Hamann (J.) and Tolle (A.) (1978). - 20th Int. Dairy Congr., Vol. E, 79.

[243] Super (D. M.), Palmouist (D. L.) and Schanbacher (F. L.) (1976) - J. Dairy Sci., 59, 1409.

[244] Sustek (E.), Dill (C. W.) and Herlick (S. A.) (1975). - J. Dairy Sci., $58,1519$.

[245] Tallamy (P. T.) and RandolPh (H. E.) (1969). - J. Dairy Sci., 52, 1569.

[246] Tarassuk (N. P.) and Frankel (E. N.) (1957). - J. Dairy Sci., 40, 418.

[247] Tarassuk (N. P.) and Henderson (J. L.) (1942). - J. Dairy Sci., 25, 801.

[248] Tarassuk (N. P.), Laben (R. C.) and Yaguchi (M.) (1962). - 16th Int. Dairy Congr., Vol. A, 609.

[249] Tarassuk (N. P.) and Yaguchi (M.) (1958). - J. Dairy Sci., 41, 1482.

[250] Terour (M.) (1978), - Contribution à l'étude des œstrogènes chez la brebis et la truie. Thèse Doc. ès Sci., Univ, Paris VI.

[251] Thomas (W. R.), Harper (W. J.) and Gould (I. A.) (1954). - J. Dairy Sci., 37, 717.

[252] Vernon (R. G.) and Christie (W. W.) (1977). - J. Dairy Res., 44, 441.

[253] Vernon (R. G.), Clegg (R. A.) and Flint (D. J.) (1980). - Biochem. Soc. Trans., 8,370 . 
[254] Von Hippel (P. H.) and Waugh (D. F.) (1955). - J. Amer. Chem. Soc., $77,4311$.

[255] Wallinder (L.), Bengtsson (G.) and Olivecrona (T.) (1979). - Biochim. Biophys. Acta, 575, 458.

[256] Walsh (J. P.) and Downey (W. K.) (1971). - Ir. J. Agric. Res., 10, 139.

[257] Walstra (P.) (1978). - 20th Int. Dairy Congr., Doc. 75 ST.

[258] Wang (L.) and Randolph (H. E.) (1978). - J. Dairy Sci., 61, 874.

[259] Wells (M. E.), Pryor (O. P.), Haggerty (D. M.), Pickett (H. C.) and Mickle (J. B.) 1969). - J. Dairy Sci., 52, 1110.

[260] Weisenburg-Delorme (C. L.) and Harris (K. L.) (1975). - J. Nutr., 105, 447.

[261] Wooding (F. B. P.) (1975). - Bull. Féd. Int. Laiterie, Doc. 86, 7.

[262] Wooding (F. B. P.), Morgan (G.) and Craig (H.) (1977). - Cell. Tiss. Res., $185,535$.

[263] Wooding (F. B. P.), Peaker (M.) and Linzell (J. L.) (1970). - Nature, 226, 762.

[264] Yaguchi (M.), Tarassuk (N. P.) and Abe (N.) (1964). - J. Dairy Sci., 47, 1167.

[265] Yang (Y. T.), Baldwin (R. L.) and Garrett (W. N.) (1978). - J. Anim. Sci., 47, 686 . 